\title{
Unpacking Design-Build Nomenclature
}

The term design/build is a slight misnomer for these courses, which are intended less as surveys of the popular alternative delivery method than as hands-on clinics to teach students about sites, structures, materials, and joinery. Academic design/build programs remove design projects from the studio vacuum and push students to reconcile their drawings with real structures they can build, weld, wire, and plumb. They encourage students to work as part of collab-orative teams, resolving conflicts, managing finances, and communi-cating with clients. ${ }^{1}$

Academics and construction industry professionals both use the term 'Design-Build' but the term is used differently by each group to describe two distinct operational strategies. In the construction industry, "Design-build is a method of project delivery in which one entity- the design-build team- works under a single contract with the project owner to provide design and construction services." 2 In contrast, design-build in schools of architecture refers to a teaching method distinguished by the integration of hands-on, full-scale construction as a fundamental component in the design process. In practice, confusion arising from this semantic overlap is limited by the fact that academic faculty and building contractors seldom intersect in daily practice.

However, as design-build education has expanded rapidly over the last twenty years there is growing confusion within academia with regard to both the fundamental core tenants and the limits of the pedagogical model. Twenty years ago William J. Carpenter's seminal Learning by Building: Design and Construction in Architectural Education established a working definition for contemporary Designbuild courses in architectural education by referencing relevant precedents such as the Yale Building Program and the Rural Studio and outlining key characteristics common to the then nascent pedagogy. Carpenter's basic description highlighted construction, collabora-tion, and communication as the key differences between design-build classes and more conventional "representationbased pedago-gy" in which students work individually with a professor in a design studio setting. ${ }^{3}$

When Carpenter was writing in 1997 there were a handful of people and programs, less than a dozen in total, experimenting with construction in architectural education.iv These programs shared, to a large degree, commonalities related to project scope, class format and pedagogy. In contrast, in 2018 nearly every school of architecture in the United States has some type of full-scale learning component in the curriculum and the pedagogy has become more common in Europe and Australia. Despite this growth, and the increased differentiation between programs vis a vis project types and pedagogical approaches, the nomenclature has not evolved to keep pace with the evident variety. As a result, to say that someone "is teaching a designbuild studio" provides little if any insight to the agenda established by the faculty member.

Michael Hughes

American University of Sharjah 


\section{DESIGN BUILD EVOLVES}

The expanding field of distinct methods, project types, and intellectual goals coincides with the rapid expansion in the number of teacher/practitioners and design-build programs. As more schools offer courses and more faculty become involved the range of course objectives and outcomes have evolved to include a broad range of activities and foci. Today faculty operating nominally under the design-build nomenclature, or categorized as such on a superficial level, are often pursuing radically distinct agendas. Even within indi-vidual schools or programs projects evidence divergent or conflicting trajectories.

For example, a close examination of projects completed at Auburn University's Rural Studio reveal a number of different directions explored since Samuel Mockbee established the program in 1993. Across twenty plus years the accumulated evidence shows that some projects privileged reuse and recycling while others foreground tec-tonic detailing, vernacular typologies, material experimentation, low cost housing, landscape or social engagement. Some privilege poet-ic expression and experimentation, with results that exhibit what Andrew Freear "decries as 'shanty architecture', while others mani-fest precise detailing and craftsmanship.v These dichotomies can be found in projects completed in the same time period as well as across the twenty-five year history of the Rural Studio.

Even the internal organizational structure changes in terms of the number of students, scope, and duration to accommodate two distinct groups of students, (2nd or 3rd year undergrads versus 5th year thesis students). In addition, Rural Studio projects have been led by a number of faculty including David Buegee, Frank Flurry, Emily McGloem and Xavier Vendrell who bring their individual agendas to the work. The extraordinary range of results belies any singular or repetitive methodology.

At the American University of Sharjah a rotating cast of six to eight faculty with differing skill-sets and capacities coexist within the Department of Architecture's Design Build Initiative. Supported by an extensive array of analog and digital fabrication equipment participat-ing faculty pursue a broad range of issues around fabrication. Some pursue more conventional furniture or installation projects featuring traditional materials and analog tools while others focus on a particu-lar material, (sheet metal, fiber resin composites, wood), process, (cast-ing, aggregate assembly, carving) or tool (CNC routers, 5-axis milling machines and waterjet cutters). Still others prioritize issues such as sustainability, housing, and landscape and yet they are all convention-ally lumped together under the broad term "design-build."

\section{ATTEMPTS AT CODIFICATION}

Presenters at the June 2016 "Hands On: Enhancing Architectural Education" Conference held at the Technical University Vienna repre-sented a cross-section of subthemes loosely organized in three the-matic sessions titled Learning through Making, Pubilc Interest Design: Collective Action and Social Engagement through Architectural Education, and Hands On Education Beyond the Institution. While presentations in the Public Interest Design session coalesced around the subtheme of community engagement presentations in the other sessions lacked cohesion. One presentation clearly focused on digital fabrication was positioned next to work emphasizing cultural immer-sion in an unfamiliar context. Another focused on curricular develop-ment while others focused on social development.

The resulting juxtapositions led to a messy, but revealing set of discussions. At one point during the discussion following Martin Self's presentation of the technologically advanced work happening in the Architectural Association's (AA) Hooke Park Design \& Make pro-gram at the AA School of Architecture an audience member asked if the work had any broader social or community benefit. Professor Self explained that the program focused on applied research bracketed by digital fabrication and the existing timber resources in the Hooke Park managed forest. In response the audience member suggested that community engagement was fundamental to all design-build peda-gogies and as such the Hooke Park work was not admissible.

In contrast, the October 2016 "Experiential Learning in Architecture and Environmental Design Education" Conference held in Lyon France featured a keynote address on design-build edu-cation by Bryan Mackay-Lyons, founder of the Ghost Architectural Laboratory in Canada. At the Ghost Lab Mackay-Lyons focuses on design build the act of making and the 'master builder tradition. All projects occur on private property for a private client with no ele-ment of social outreach or community engagement.

These examples highlight the growing disparities and sub-currents within design-build pedagogy. Similar discussions within these conferences considered the validity of projects in terms formal or spatial quality, material and tectonic craft, and disciplinary innovation versus course objectives that highlight exposure to underrepresented com-munities, participatory processes, and social interactions between students and clients. As speakers, panelists and audience members expressed their preconceptions and biases they collectively exhib-ited the variety and pedagogical diversity now existing in design-build education.

Increasingly, alternative frameworks have grown out of the design-build tradition, or been developed in parallel, in an effort to distin-guish and define operational and strategic parameters. For example, the Live Projects model now common in Britain and Australia privileg-es learning through engagement with real projects and clients, but do not require a full-scale building component. Jane Anderson and Colin Priest have defined conditions "common to all Live Projects: exter-nal collaborator, educational organization, brief, timescale, budget and product" vi. Similarly, the Public Interest Design sub-theme has evolved to privilege community engagement and the role of people, or the public, in the design and decision-making process vii.

Rather than articulating an alternative framework Chad Kraus attempts to reinforce a limited set of essential conditions presum-ably shared by all design-build educators. In the introduction to Designbuild Education Kraus asserts "four essential themes" that "thread through the majority of designbuild initiatives in vary-ing degrees of intensity. These motivations...tend to stress a reen-gagement with people, poetics, process, and practice."viii The book goes on to showcase a series of case studies intended to serve as, 
"testaments to the pedagogical benefits of design-build education ix. As such the text serves primarily to promote a singular pedagogical model rather than reveal distinctions.

\section{SUBTHEMES}

In contrast to the evolving and expanding range of objectives and working methods evident in design-build pedagogy the nomenclature remains unchanged and largely inarticulate. Equally, literature on the topic has tended to focus on the operational methods and result-ing projects rather than an articulation of differing agendas, peda-gogical goals or theoretical underpinnings that structure the work of specific design build teachers and programs.

While the majority of design-build faculty maintain allegiance to material construction and the experiential teaching methods inspired by John Dewey's learn by doing ethosx, defaulting to a single descrip-tion in reference to any project that includes a full-scale construction component risks oversimplification. By analogy, all design studios that utilize a particular instrument, be it a pencil or a software program, do not constitute a movement. Similarly it would be difficult to describe the range of inquiry happening in hypothetical design studios with-out additional qualifiers: Comprehensive, Paperless, Speculative, Technical, Structures, Community Design, Typological, Tall Buildings, Form Finding, Scripting, Core, Distinguished Visiting Critic, Travel or Study Abroad, etc. The diversity evidenced by design-build practitioners demands a more nuanced set of descriptors.

A careful analysis of existing design-build endeavors reveals a diverse range of subthemes operating under the design-build umbrella that have evolved over the past twenty years. These subthemes present an opportunity to unravel and identify the primary objec-tives evident in contemporary design-build coursework. A review of existing literature and design-build programs including published articles, books and school websites reveal an initial list of nine clear subthemes. In addition to the most common format described in Carpenter's 1997 text, which we could call "Master Builder" (1), these subthemes include (2) Sustainability, (3) Material Experimentation, (4) Digital Fabrication, (5) Low-cost Housing, (6) Landscape, (7) Cultural Immersion and (8) Interiors along with those that foreground (9) Social Outreach and Community Engagement. While the majority of design-build programs evidence some combination of these subthemes the categories serve to expose the range of divergent, even contradictory agendas operating under the shared, imprecise nomenclature.

\section{EXAMPLES}

A number of these subthemes are evident in projects completed at the Rural Studio. Early projects such as the Cardboard Sleeping Pod, Glass Chapel and the Yancy Tire Chapel focus on sustainability through the use of salvaged and reused materials while more recent projects at Perry Lakes Park and the Rural Heritage Center feature exquisite craft and detailing common to the master builder tradition. Material exper-imentation is evident solid timber construction of the Newbern Town Hall and the lamella truss structure of the Hale County Animal Shelter while low cost housing is the primary focus of the $20 \mathrm{k}$ Houses.
In addition to material reuse the sustainability subtheme contains a variety of approaches. The Solar Decathlon compe-tition highlights active sustainability while projects completed by the Drachman Design-Build Coalition at the University of Arizona focus on passive energy efficient strategies through solar orientation, shading and material performance. Studio 804 at the University of Kansas explores sustainability through projects that combine passive and active methods to meet stringent LEED Platinum and Passive House certification.

The Design + Make program at Architectural Association, mentioned above, and the Design Fabrication Laboratory (dFAB) at Carnegie Mellon University engage emerging dig-ital fabrication technologies applied at the scale of installa-tions, prototypes and realized buildings. Projects completed by Emily Baker and Ken Tracy at the American University of Sharjah also utilize digital fabrication, but the focus more narrowly on a specific material, sheet metal, and tool, a 400 watt CNC laser, capable of cutting through sheet metal. Similarly, faculty at the University of Michigan conduct research focused on exploring the capacity of the school's 5- and 7-axis Kuka robots.

\section{CONCLUSION}

While not nearly exhaustive the examples provided illustrate the expanding range and diversity existing within contemporary design-build education. As the novelty wears off and the pedagogical model matures critical discourse needs to evolve in order to more precisely articulate and explain important distinctions within the sub-discipline. Improvements in the quality of critical assessment and critique are necessary to develop coherent operational theories, participate in ongoing debates in the field of education, and elevate the discourse such that design-build practitioners can more fully engage academic scholarship.

Without a coherent language, or lexicon, design-build faculty risk being perceived as existing outside the norms of academic research. This otherness poses significant challenges for those seeking tenure and promotion at conventional research universities where design-build is often relegated to service or teaching rather than scholarship. Further, additional descriptive precision provides an opportunity to clarify, com-pare and differentiate intentions and outcomes.

\section{Notes}

1. "Learning from Construction", Architecture (September 1996), p 145

2. "What is Design-Build?" About DBIA. DesignBuild Institute of America. n.d. Web. 18 May 2012. http://www.dbia.org/about/designbuild/ 
3. William J. Carpenter, Learning by Building: Design and Construction in Architectural Education, p7. (Wiley, 1997)

4. Andrea Oppenheimer Dean and Timothy Hursley, Proceed and Be Bold: Rural Studio After Samuel Mockbee, p8 (Princeton Architectural Press, 2005)

5. Andrea Oppenheimer Dean and Timothy Hursley, Proceed and Be Bold: Rural Studio After Samuel Mockbee, p12 (2005)

6. Jane Anderson and Colin Priest, Live Projects

7. Chad Kraus, Designbuild Education, p2 (Routledge, 2017)

8. Chad Kraus, Designbuild Education, p2 (Routledge, 2017)

9. Ibid

10. Dewey, John. Experience and Education(Simon \& Schuster, 1938) 